San Jose State University

SJSU ScholarWorks

Master's Projects

Master's Theses and Graduate Research

$5-21-2009$

\title{
What is the Perception of Preparedness amongst Accelerated BSN students compared to Traditional BSN students?
}

Sheetal Raman-Love

San Jose State University

Follow this and additional works at: https://scholarworks.sjsu.edu/etd_projects

Part of the Other Nursing Commons

\section{Recommended Citation}

Raman-Love, Sheetal, "What is the Perception of Preparedness amongst Accelerated BSN students compared to Traditional BSN students?" (2009). Master's Projects. 806.

DOI: https://doi.org/10.31979/etd.xzkg-n7bh

https://scholarworks.sjsu.edu/etd_projects/806

This Master's Project is brought to you for free and open access by the Master's Theses and Graduate Research at SJSU ScholarWorks. It has been accepted for inclusion in Master's Projects by an authorized administrator of SJSU ScholarWorks. For more information, please contact scholarworks@sjsu.edu. 


\section{SAN JOSE STATE UNIVERSITY SCHOOL OF NURSING}

\section{MASTER'S PROGRAM PROJECT OPTION (PLAN B)}

PROJECT SIGNATURE FORA

STUDENT NAME

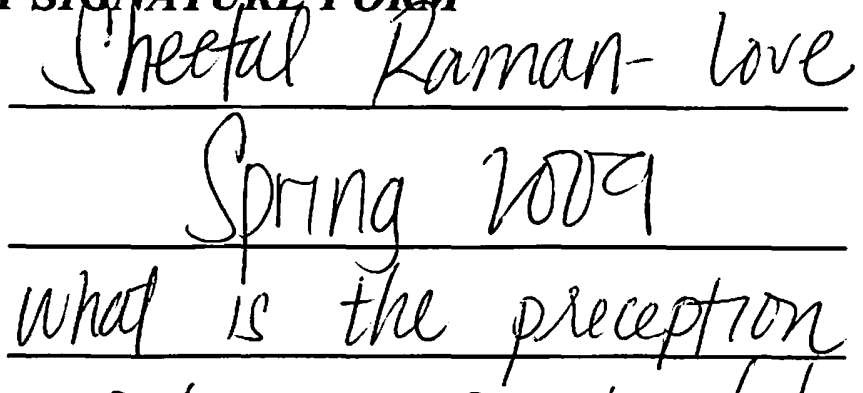

TITLE OF PROJECT

SEMESTER ENROLLED

of

\section{NAME OF JOURNAL}

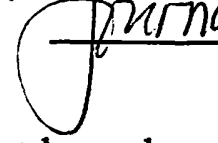

The project and the manuscript have been successfully completed and meet the standards of the School of Nursing University. The project demonstrates the application of professional knowledge, clinical expertise, and scholarly thinking. An abstract of the project and two copies of the manuscript are attacheed

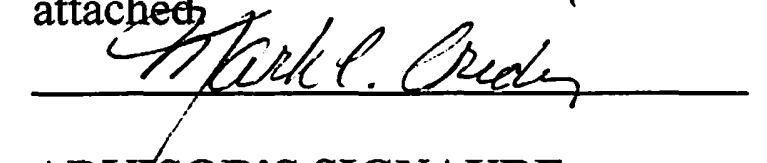

ADVISOR'S SIGNAURE

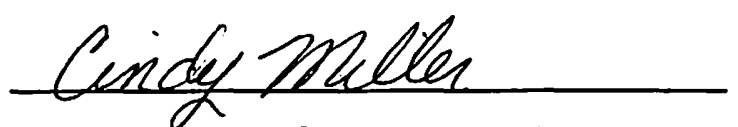

ADVISOR'S SIGNAURE

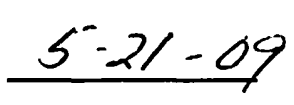

DATE

$$
5-21-09
$$

DATE

Please submit the form to the Graduate Coordinator. Attach abstract, two copies of the manuscript, and the documentation of submission to the journal (i.e., postal receipt or email). 


\section{Master's Project:}

What is the Perception of Preparedness amongst Accelerated BSN students compared to Traditional BSN students?

Presented to

The Faculty of the Division of Health Professions

San Jose State University

In Partial Fulfillment

of the Requirements for NURS 297

By

Sheetal Raman-Love

May 21, 2009 


\begin{abstract}
$\underline{\text { Abstract }}$
With today's economic uncertainty, and nursing shortages, many have decided to join the health care industry in hopes of finding financial stability and job security. The impaction of nursing schools throughout the United States has led to the proliferation of accelerated nursing programs. These programs are designed for motivated students who are able to utilize their prior educational experience enabling them to accelerate and complete their BSN degree in a short period of time (Wu, C.Y., \& Connelly, C.E., 1992).
\end{abstract}

This study focused on the examination of the length of time in nursing school and the potential influence it may have on students' perception of preparedness. A 24-multiple choice questionnaire was distributed to graduating accelerated and traditional BSN students $(n=71)$ at San Jose State University's School of Nursing. Statistical analysis of the data supports that accelerated BSN students and traditional BSN students have some variances in their perception of preparedness and educational satisfaction.

\title{
$\underline{\text { Research Problem }}$
}

With shortages of nurses throughout the United States, many schools have adopted accelerated Bachelor of Science (BSN) programs. These accelerated programs tend to range in duration from thirteen to eighteen months and were originally created for those with a bachelor's degree in another field (Seldomridge, L.A., \& Dibartolo, M. C., 2005). These programs are designed to graduate students in a condensed time frame and prepare them as entry level nurses. This study however attempts to examine accelerated BSN students who are not required to have a bachelor's degree already in place. Instead, the only required differences separating the 
accelerated program from the traditional nursing program is the length of schooling requisite, and that all university general education courses must be completed prior to beginning the accelerated program. Although several students at San Jose State's School of Nursing did enter the program with an earned bachelor's degree in another field (9), this study only focused on the students in the accelerated program who were first baccalaureate students (29).

Students in accelerated BSN programs are challenged to learn the knowledge and skills necessary to become competent, entry level Registered Nurses in as little as thirteen to eighteen months. This study explored the perception of preparedness between accelerated BSN students and traditional BSN students. The research explored this perception within a single urban university school of nursing, and contributes to the discussion and body of knowledge of nursing's entry educational programs. Although accelerated BSN programs throughout the United States have been examined, little research has been done examining accelerated students and their educational experience (Cangelosi, P.R., \& Whitt, K.J., 2005).

\section{Literature Review}

This study defined 'preparedness' as a sense of confidence in being ready to perform in the position of a registered nurse. A computerized search of CINAHL, ERIC, Medline, and Wilson Web databases from 2004 to 2009 revealed a modest amount of literature devoted to both accelerated and traditional BSN programs and students. Key words searched in the databases were, accelerated BSN students, traditional BSN students, curriculum, student satisfaction, student preparedness, nursing school, educational experience, and nontraditional students. This yielded a number of research studies devoted to the two types of BSN programs. The literature 
predominantly examined accelerated nursing students who had previously obtained a bachelors degree outside the field of nursing.

The accelerated baccalaureate nursing curriculum was first introduced in the United States in 1971 at Saint Louis University School of Nursing. The program's objective was to increase the supply of baccalaureate-prepared nurses by recruiting individuals with non-nursing baccalaureate degrees into their nursing program (Meyer, G.A., Hoover, K.G., \& Maposa, S., 2004). The accelerated students were required to complete the nursing program in a twelve month period, whereas the traditional BSN program was three years. The success of accelerated nursing programs has fueled the steady increase in the continuous development of more accelerated nursing programs throughout the country (2004).

Registered Nurses, hospital administrators, and nursing faculty have all questioned the feasibility of graduating competent, entry-level professional nurses with as little as one calendar year of nursing course work (Cangelosi, P.R., \& Whitt, K.J., 2005). Academically, however, studies have indicated that accelerated students score higher on the standardized nursing achievement test and have higher pass rates on the National Council Licensure Examination for Registered Nurses (NCLEX-RN) compared to traditional nursing students (2005). A research study conducted by Seldomridge and DiBartolo, (2005), found that the accelerated students' NCLEX-RN pass rate of $84.2 \%$ was slightly higher than the pass rate of the traditional students' 80.6\%. Aside from NCLEX-RN scores, research also indicated that the grade point averages (GPAs) of accelerated students were significantly higher than those of traditional students (Cangelosi, 2005). Statistics have indicated that although accelerated students were in nursing school for a shorter period of time, they outperformed traditionally enrolled BSN students 
(2005). These results bring into question the added value to nursing students enrolled in longer, traditional BSN programs.

Other researchers have followed accelerated BSN students post graduation. Raines (2007) examined graduates from accelerated BSN programs to determine if they felt their educational experiences prepared them as skilled nurses. The research showed that students' perception of their course satisfaction remained positive one year post graduation. Student satisfaction has been correlated with improved retention and contributes to academic, personal, and professional achievement (Corts, D., Lounsbury, J., Saudargas, R., \& Tatum H., 2000). Student perception of satisfaction with accelerated BSN programs and the effectiveness of their educational experience have been demonstrated to be an important and reliable indicator in the evaluation of the educational program (Raines, 2007). With the constant increase in accelerated BSN programs, it is important that students' level of satisfaction and perception of preparedness be evaluated. This study aimed to evaluate students' perception of preparedness when enrolled in a traditional BSN program compared to the students enrolled in an accelerated BSN program. Subsequently, this research can contribute to the evaluation of an accelerated BSN program.

\section{Methodology}

Sampling for this study consisted of 71 graduating students enrolled in San Jose State University's School of Nursing program. Twenty-nine students were enrolled in the eighteen month accelerated program, and 42 students were enrolled in the traditional three year program. A survey was distributed amongst the students during their last week of school. The students were asked to reflect upon their entire nursing school experience and complete a 24 multiplechoice questionnaire. Each question required a Likert-scale response of 1, 2, 3, 4, or 5; (1: 
strongly disagree and 5: strongly agree). The survey also provided students with the opportunity to write about aspects of the program that they felt were helpful and where they felt the program needed improvement. Surveys were distributed during the students' scheduled class time. The students were allotted as much time as they needed to complete the survey and the responses were anonymous. The researcher distributed the survey amongst the students enrolled in the traditional BSN curriculum, and a nursing faculty member distributed the survey amongst the students enrolled in the accelerated BSN program. Prior to the distribution of the survey, the researcher informed the faculty member the purpose of this study and clarified instructions as to how to properly complete the survey. This allowed students from both groups to receive the same information, and allowed for congruency amongst the proctors.

The researcher utilized the Course Experience Questionnaire (CEQ). The CEQ was developed by Paul Ramsden in 1992, and has since been administered as a part of an annual national survey to all the graduates from all Australian universities. The CEQ gathers information about graduates' perceptions of their learning experiences. The survey is designed to measure and quantify specific outcomes of education such as graduate satisfaction with teaching and learning in courses (Ramsden, 1991).The CEQ is considered a valuable instrument for the purpose of improving the quality of teaching in universities, managing institutional performance, and promoting accountability within the higher education sector (1991).

The development and validation of the CEQ has been studied and reported extensively (McInnis, C. Griffin, P.; James, R.; \& Coates, H., 2001). There is now over 20 years of research evidence which supports the theoretical and empirical basis of the Course Experience Questionnaire (www.dest.gov.au). The most common use of the CEQ results is for interinstitutional benchmarking for best practice within fields of study (Wilson, K.L., Lizzio, A., \& 
Ramsden, P., 1997). Institutions can also use the results of the CEQ to provide information on the benefits and constraints of particular courses (Griffin, P.; Coates, H.; McInnis, C.; \& James, R., 2003). The results can provide information that indicates where improvements in satisfaction of a course experience and consequently program improvement can be made, particularly as it relates to quality of teaching (Trembath, 1998).

The CEQ consists of 24 statements relating to the students' learning experience in the areas of: teaching, expected standards, assessment, workload, the development of generic skills, and an overall satisfaction statement. The grouping of the questions is illustrated in table one.

Table 1.

\section{Good Teaching scale}

The teaching staff of this course motivated me to do my best work.

The staff put a lot of time into commenting on my work.

The staff made a real effort to understand difficulties I might be having with my work

The teaching staff normally gave me helpful feedback on how I was going.

My lecturers were extremely good at explaining things.

The teaching staff worked hard to make their subjects interesting.

Clear Goals and Standards scale

It was always easy to know the standard of work expected.

I usually had a clear idea of where I was going and what was expected of me in this course.

It was often hard to discover what was expected of me in this course.

The staff made it clear right from the start what they expected from students.

Appropriate Workload scale

The workload was too heavy.

I was generally given enough time to understand the things I had to learn.

There was a lot of pressure on me to do well in this course.

The sheer volume of work to be got through in this course meant it couldn't all be thoroughly comprehended.

Appropriate Assessment scale

To do well in this course all you really needed was a good memory.

The staff seemed more interested in testing what I had memorized than what I had understood.

Too many staff asked me questions just about facts.

\section{Generic Skills scale}

The course developed my problem-solving skills.

The course sharpened my analytic skills.

The course helped me develop my ability to work as a team member.

As a result of my course, I feel confident about tackling unfamiliar problems.

The course improved my skills in written communication.

My course helped me to develop the ability to plan my own work.

Overall Satisfaction

Overall, I was satisfied with the quality of this course. 


\section{$\underline{\text { Results }}$}

Initially a pair- wise calculation of the mean and standard deviations for each of the six categories was compiled for both groups of students. Two sample t-tests were done in order to see if variance between the two groups existed. Type one error was addressed by using a p-value of 0.05 as the benchmark between data being statistically significant and not significant. A pvalue less than 0.05 was considered to be statistically significant at a five percent confidence and $\mathrm{p}$ values below 0.01 were considered highly significant. According to the calculated data, there were significant differences between the traditional and accelerated students in three categories. Data is reflected in table two.

\section{Table 2.}

\begin{tabular}{|c|c|cc|cc|cc|}
\hline \multirow{2}{*}{ Category } & Description & Traditional & Accelerated & \multirow{2}{*}{ t } & p \\
\hline I & Geans & SD & Means & SD & & \\
II & Good Teaching & 21.31 & 4.33 & 20.90 & 2.45 & 0.46 & 0.644 \\
III & Appropriate Workload & 14.38 & 2.56 & 14.34 & 1.72 & 0.07 & 0.947 \\
IV & Appropriate Assessment & 8.31 & 2.88 & 14.00 & 1.85 & 0.08 & 0.938 \\
V & Generic Skills & 23.21 & 4.11 & 10.72 & 1.49 & -4.18 & $\mathbf{0 . 0 0 0}$ \\
VI & Overall Satisfaction & 3.90 & 0.91 & 3.41 & 2.38 & 2.61 & $\mathbf{0 . 0 1 1}$ \\
& & \multicolumn{1}{|c|}{} \\
\hline
\end{tabular}

No statistical significance was found within the Good Teaching category, the Clear Goals and Standards category, or the Appropriate Workload category. The Appropriate Assessment Scale category had a p-value of 0.000 , which proved to be the greatest statistical variation between the accelerated students and traditional students. High statistical significances were also found within the Generic Skills category which had a $p$ value of 0.011 and within the Overall Curriculum Satisfaction category which had a p-value of 0.01 . 
The written portion of the survey asked two questions: (1) what was the best aspect of this course, and (2) what aspects of this course are most in need of improvement? The responses from students in both groups varied from being satisfied with the program to being completely dissatisfied. For the most part students enrolled in the traditional program valued the hands on experience they gained during their clinical rotation. Comments included, "The clinical experience was the most valuable aspect of the program," and "The hands on experience were great and clinical instructors generally gave a lot of feedback." On the other hand, poor preparation for the following semester was predominately the frustration felt by the traditional students. Students wrote, "I felt that we needed more hours in skills and pharmacology to better prepare us for clinical next semester," and "We were not being told what to expect the next semester and we felt lost."

Accelerated students commented on a variety of beneficial aspects of the course. One student wrote, "I felt that the instructors were really there for us." Another student wrote, "I liked knowing that I was going to be done soon," and "I learned a lot during my clinical." Feelings of being overwhelmed seem to be the general feeling amongst accelerated students. One commented, "Sometimes I felt that the program was so fast, that I did not know what was important to remember." Another student wrote, "The instructors were helpful but I usually felt overwhelmed."

The written portion of the survey allowed the researcher to get a better feeling as to how the students felt about their program. Students were able to describe their feelings without being confined to predetermined responses. 


\section{Discussion}

Accelerated and traditional BSN students at San Jose State University's School of Nursing had similar perceptions about their encounters with staff members. Students felt their instructors motivated them, invested substantial amount of time commenting on their work and provided them with helpful feedback. Similar perceptions about clear goals and appropriate workload were also shared amongst the accelerated and traditional students. Both groups of students knew what was expected of them throughout the program, and the volume of work was appropriate for their level of expertise.

The greatest statistical variation was found in the Appropriate Assessment category. Accelerated students felt that the tools used to assess their knowledge were based primarily on what the students knew rather than their thought process. The students felt that the instructors were more interested in what the students had memorized rather than what they had actually understood. The accelerated students felt that in order to succeed in the program all they needed was a good memory. In contrast, the traditional students felt that the tools used to assess their knowledge were appropriate.

The traditional students seemed to have benefited the most from their nursing curriculum in regards to developing and enhancing their generic skills. These students felt that the nursing program helped to develop their analytical skills, problem-solving skills, and their ability to work as a team member. One explanation as to why the traditional students felt that their skill level increased compared to the accelerated group of students may be related to the length of the nursing program. Traditional BSN students were in school twice as long as the accelerated 
students, providing the traditional students with more time to develop such skills. Generally, the accelerated students did not feel that the nursing curriculum helped to enhance their skill level.

Overall curriculum satisfaction was found primarily amongst the traditional BSN students. Again, this may be attributed to the longer time spent in the nursing program. This extended program time may have helped the traditional students to participate in a greater number of opportunities that contribute to building stronger relationships with faculty and peers which may have enhanced their overall feelings of satisfaction with the program.

\section{$\underline{\text { Conclusion }}$}

The utilization of the Course Experience Questionnaire allowed the researcher to examine the possibility of perceptual differences among San Jose State's School of Nursing accelerated and traditional BSN students. Results from this survey demonstrated a statistically significant difference between the student groups in relation to their perception of preparedness in three of six categories, and overall course satisfaction. Differences in student perception of preparedness between accelerated BSN students and traditional BSN students is a valuable area of study in the development of nursing curriculums. Limitations for this study include a small sample size, and the examination of students from one nursing program. Student survey responses may also have been influenced by the distribution of the survey during the final week of school, when pending final examinations are likely contributing to student anxiety. This study does, however, support the need for further research examining the time spent in nursing preparation and its influence on student outcomes and professional nursing practice. 


\section{$\underline{\text { References }}$}

Cangelosi, P.R., \&Whitt, K.J., (2005). Accelerated nursing programs what do we know? Nursing Education Perspectives, 26 (2) pp 113-116.

Corts, D.; Lounsbury, J.; Saudargas, R.; \& Tatum H., (2000). Assessing undergraduate satisfaction with an academic department: A method and case study. College Student Journal, 34, pp. 399-409.

Development of the Course Experience Questionaire. Retrieved January 21, 2008, from www.dest.gov.au/archive/HIGHERED/eippubs/eip01_1/01_1.pdf.

Griffin, P., Coates, H., McInnis, C., \& James, R. (2003). The development of an extended course experience questionnaire. Quality in Higher Education, 9(3), 259-266.

McInnis, C., Griffin, P., James, R., \& Coates, H. (2001). Development of the Course Experience Questionnaire (CEQ). Melbourne: Higher Education Division, Department of Education, Training and Youth Affairs

Meyer, G., \& Hoover, K.G., \& Maposa, S., (2006). A profile of accelerated BSN graduates, 2004. Journal of Nursing Education, 45 (8) pp. 324-327.

Raines, D.A., (2007). Accelerated second-degree program evaluation at graduation and one year later. Nurse Educator, 32 (4) pp.183-186.

Ramsden, P. (1991). A performance indicator of teaching quality in higher education: the course experience questionnaire. Studies in Higher Education, 16 (2), 129-150.

Seldomridge, L.A., \& DiBartolo, M.C., (2005). A profile of accelerated second bachelor's degree nursing students. Nurse Educator, 30 (2), pp 65-68.

Trembath, K. (1998). Enhancing the CEQ: Enhancing and customising the analysis of the CEQ. Paper presented at the Proceedings of the Course Experience Questionnaire 
Symposium, New South Wales, 93-98.

Wilson, K.L., Lizzio, A., \& Ramsden, P. (1997). The development, validation and application of the course experience questionnaire. Studies in Higher Education, 22 (1), 33-53.

Wu, C.Y., \& Connelly, C.E. (1992). Profile of non-nurse college graduates enrolled in accelerated baccalaureate nursing program. Journal of Professional Nursing, 8, 35-40. 